\title{
Performance analysis of Dropped Packets for Location Aided Routing Protocol Using Artificial Intelligence
}

\author{
Neelima Parsendia ${ }^{1}$, Amit Sinhal ${ }^{2}$,Neetesh Gupta ${ }^{3}$ \\ ${ }^{1,2,3}$ Dept. of IT, Technocrats Institute of Technology, Bhopal
}

\begin{abstract}
Location aided routing protocol (LAR) is an on demand protocol in MANET which uses GPS in mobile nodes to find the location of node. It calculates routing when it is needed. LAR protocol has two zones namely expected zone and request zone. The expected zone is circular in shape while request zone is rectangular in shape. Expected zone is determined according to the location of destination and request zone is determined according to the location of source node. When communication starts between sources to destination, the node is not within expected zone; packet is dropped. Therefore, packet is lost or destroyed. This paper proposed a method for dropped packet which randomly checks exactly how many packets is dropped during transmission. This paper proposed an algorithm for wireless LAN.
\end{abstract}

Keywords: Expected zone, GPS, MANET, Request zone, Wireless LAN.

\section{INTRODUCTION}

A wireless LAN or WLAN is a wireless local area network, which is the linking of two or more computers without using wires. WLAN utilizes spread-spectrum or OFDM (802.11a) modulation technology based on radio waves to enable communication between devices in a limited area, also known as the basic service set. This gives users the mobility to move around within a broad coverage area and still be connected to the network. WLAN also uses LAR routing protocol for knowing location of destination.

Location aided routing protocol is an ad hoc routing protocol which requires route when it is transmitted packets to the destination node. Basically, LAR used to find location of node while using GPS in mobile node. The mobile nodes are used for communication from one node to another node. Using GPS in mobile nodes we can find exact location of destination node. Like DSR, LAR protocol uses flooding algorithm to broadcast the message. LAR sends location information in all packets to (hopefully) decrease the overhead of a future route discovery [1]. It utilizes location information to limit the route query flooding area. The prerequisite is that every host knows its own location and the global time, which can be provided by a Global Positioning System (GPS). When node $\mathrm{S}$ wants to send messages to node D, it will broadcast a route query message, which is forwarded only by the nodes in the "request zone." When a node forwards the route query, it appends its node ID to the head of the packet. After node D finally receives the route query, it sends a route reply back to the source node S using the reverse path which is recorded in the head of the route query packet. The route from $S$ to $D$ is established when the source node $S$ receives the route reply packet. LAR can efficiently reduce the RREQ flooding cost [2].

LAR protocol has two zones in which nodes are moved i.e. expected zone and request zone.

\section{A .Expected Zone}

Expected zone is determined according to the location of destination. We assume that the node $\mathrm{S}$ (source) needs to find a way to node D (destination). Node S knows that D was at position L. Then, the "expected zone" of node $\mathrm{D}$, from the viewpoint of node $\mathrm{S}$, is the region that node $\mathrm{S}$ expects to contain node $\mathrm{D}$. When node $\mathrm{S}$ knows, that node $\mathrm{D}$ travels with a several speed, node $\mathrm{S}$ considers this speed to determine the expected zone of $\mathrm{D}$. When node $\mathrm{S}$ has no information about the position of $\mathrm{D}$, the entire region of the ad-hoc network is assumed to the expected zone. Then the algorithm reduces to the basic flooding algorithm. In general we can say, as more as the node $\mathrm{S}$ knows about $\mathrm{D}$, as smaller can be considered the expected zone [3].

\section{B. Request Zone}

Request zone is determined according to the location of source node. We assume that node $\mathrm{S}$ needs to find a path to node $\mathrm{D}$. Node $\mathrm{S}$ defines a Request Zone. In request zone $\mathrm{S}$ sends a route request like in the normal 
flooding algorithm. With the difference, that a node only forwards the route request to its neighbor when it is in the Request Zone. There are two different possibilities to determine that a node is 'member' of the Request Zone.

\section{B.1 LAR - 1}

This first Scheme uses a Request that is rectangular. The Node S includes the coordinates of the four corners of the Request Zone in the route request message. Node $S$ knows his own coordinates of his own GPS. The coordinates of the opposite corner becomes $\mathrm{S}$ with the corner of the Expected Zone. With these two points, Node S can make e rectangular and has the coordinates of the four corners of the rectangular. When a node with own coordinates outside of the rectangle, this node discards the route request. So the flooding of the ad-hoc network is reduced. When route request sent by node $\mathrm{S}$ is arrived at node $\mathrm{D}$ and replies with a route reply message. Node D includes in this route reply message its current location the time where the message is sent. S, when node $\mathrm{S}$ receives this message and records the location of $\mathrm{D}$ and $\mathrm{S}$ can use it to determine the Request Zone in a future route discovery [4].

\section{B.2 LAR -2}

In this scheme of the LAR protocol node $\mathrm{S}$, who will find a path to $\mathrm{D}$, knows the location $(\mathrm{Xd}, \mathrm{Yd})$ of D. With this coordinates, node S calculates the distance from D (DISTd). Both, the coordinates and the distance are included in the route request. Now, when a node receives the route request from $\mathrm{S}$, it calculates the distances between itself and D. When this distance as larger then DISTd from node $\mathrm{S}$ it discards the route request. Otherwise it sends the route request with included its own distance to $\mathrm{D}$ and the coordinates of $\mathrm{D}$ to his neighbors. So the route request will arrive at node $\mathrm{D}$ and route reply will be send back to S[4].

The rest section of this paper is as follows: Previous work described in section 2, proposed work explained in section 3. Simulation setup and results described in section 4 and finally section 5 concluded this paper.

\section{PREVIOUS WORK}

Location-aided routing (LAR) is a mechanism which attempts to reduce the control message overhead of Ad-hoc on-demand distance vector (AODV) routing protocol by flooding only the portion of the network that is likely to contain the route to destination. LAR takes advantage of Global Positioning System (GPS) coordinates to identify a possible location of the destination node. Based on this information, LAR defines a portion of the network which will be subject to the limited flooding, thus reducing the total number of the control packet traveling through the network during the route discovery process. Geo AODV is a variation of the AODV protocol which like LAR also employs GPS [5] coordinates to limit the search area used during the route discovery process. However, unlike LAR, Geo AODV does not make the assumption that every node in the network knows the traveling speed and location of the corresponding destination node. Instead, Geo AODV tries to dynamically learn and distribute location information among the nodes in the network. This paper examines and compares through simulation the performance of AODV, LAR, and Geo AODV protocols [6].

F. De Rango, proposed class of routing algorithms using information about geographical location of the mobile nodes in wireless ad hoc networks. They proposed a modification in the way of re-computing the forwarding zone of route request packets for the location-aided routing (LAR) protocol. The shape and extension of this zone influences the protocol performance in terms of control overhead, packet delay and loss and also study the impact of a multi-step resizing of the request zone on the LAR protocol performance, and make comparisons with other routing protocols (such as the original LAR scheme 1 and the promiscuous-dynamic source routing protocol). Simulation results show how our approach adds to the advantages of LAR scheme 1 the further advantage of reducing the control overhead [7].

F. De Rango contributed the issue of location-aided routing in ad-hoc wireless networks. It focuses on the location-aided routing (LAR) protocol and its way of building the forwarding zone. A modified-LAR algorithm is proposed and three variants of it are examined. All of them are based on the idea of enlarging the request zone, in case of failure of the route discovery phase, instead of restoring to flooding. Simulation results show that the proposed algorithm leads to an improvement in the control overhead [8]. 
Vyas and Mahgoub presented a location and mobility pattern based routing algorithm for MANET. The proposed algorithm was an enhancement of the LAR algorithm that utilizes both location information as well as mobility pattern of mobile hosts to further reduce route discovery overhead. The results showed reduction in the routing messages when the information of predictable mobility pattern of the mobile hosts is utilized [9].

Dipankar Deb has presented an algorithm which is location aided and also energy efficient. This approach is applicable in GPS scarce network. The major contribution of the work is in proposing a new location aided routing methodology that is energy efficient too. The positioning framework that this new protocol uses is suitable for GPS scarce environment. The proposed LACBER is a better location aided routing protocol comparing LAR in terms of lower hop-count and improved energy utilization. The solution is low cost and energy efficient. The GPS enable nodes wakes up periodically to listen for changes and goes back to the sleep mode to conserve energy. The location information helps keeping the number of control message exchanges low during the route discovery process. This is useful for better utilization of bandwidth [10].

\section{PROPOSED WORK}

This paper proposed a solution for dropped packets in LAR routing protocol during transmission using worst case of artificial intelligence. The proposed algorithm increase probability to search node for one place. This work has proposed algorithm for expected zone of LAR protocol. The expected zone is circular region where destination may be move from the point of view source node. This region is divided into four segments because it does not cause interference.

\section{ALGORITHM 1}

If the source wants to send data

The proposed system has some information before sending data packets to the destination.

- $\quad$ Each host still has a unique ID (such as IP address or MAC address).

- To be location-aware, each mobile host is equipped with a positioning device such as a GPS receiver from which it can read its current location.

- Each node knows their maximum distance for communication, according to their transmitter power.

Let a node $\mathrm{S}$ has to transmit the packet to destination $\mathrm{D}$, now two possibilities arrives.

1) The $S$ knows the coordinates of $D$. or

2) The $\mathrm{S}$ doesn't know the coordinates of $\mathrm{D}$.

The $\mathrm{S}$ will transmit the RREQ packet with (source address, source location, destination address, destination location, packet number, Padd, Ploc) in above mentioned case 2 it will transmit the zero filled data for destination location.

The following step is required for proposed work:

1) Consider that source node $S$ wants to transmit packet to the destination node $D$.

2) The source node selects the destination which has to be transmitted the packet during transmission.

3) If source node knows the location of destination, it sends the RREQ message along with packet number \& Address and Location of D, Otherwise

4) It sends the RREQ with Address of D.

5) The intermediate node $P$ receives this RREQ packet.

6) If transmitting range of $P$ is greater than distance between $P$ and $S$ it will drop the packet otherwise.

7) The intermediate node $P$ forwards the RREQ packet to the destination node with max PDF.

8) The process is continued till the destination node $\mathrm{D}$ found.

The above step is repeated until destination node received the RREQ packet and then process is completed. 


\section{ALGORITHM 2}

\section{If the node receives a packet}

The identification of random packet drops helps in determining the node which are not fully compromised but at times result in dropping of packets randomly. The identification of these dropped packets is facilitated using worst case $\mathrm{O}(\mathrm{n}) 2$ in algorithm where $\mathrm{n}$ is the number of packets dropped in transmission. The algorithm begins at the source node which needs to send packet number with RREQ message to its neighbors. Each time packets is sent, the counter value is increased. A mismatch of this value between the current node and the previous node at any point of the time indicates random drop packets in path.

\section{Algorithm}

1) Detect if packets were dropping during transmission from source node $S$ to intermediate node $P$.

2) Transmit packet from node to $S$ to intermediate node $P$ along with path.

3) If number of packets is received not equal to the packet count at current node.

4) Process Route Request.

5) Process Route Reply.

6) Process Data Packet.

7) Process Acknowledgement and return true otherwise return false.

8) Process Route Disconnect.

9) Process Route Disconnect reply.

10) Process Timer Run Out

\section{A. Simulation Setup}

\section{SIMULATION AND RESULTS}

Network simulation provides a means of testing proposed changes prior to placing them into effect, performing what-if analysis concerning the reliability of key components in a network and the effects of losing a component, planning for future growth, and initial design of a proposed network. The costs associated with the building and operating of a network make simulation a viable option in making choices in the building, modification, and performance analysis of a network.

To implement this paper, the most popular network simulation software OPNET Modeler is used to simulate LAR and proposed LAR routing protocol of the mobile ad hoc network and compare performance.

The simulation environment setting used in experiment is shown in table I. The simulation duration is 30 minutes and the network area is $1 \mathrm{~km} \mathrm{x} 1 \mathrm{~km}$ that includes variable number of mobile nodes ranging from 5 to 10. A Constant Bit Rate (CBR) is generated as a data traffic pattern at a rate of 1 packet per second, and $100 \%$ of the mobile nodes are selected randomly as CBR sources. The scenario of nodes mobility is generated randomly based on random way point model where a mobile node moves to a new position and pauses there for time period between 1 seconds, then it move to another position.

\begin{tabular}{|c|c|}
\hline Parameter & Setting Value \\
\hline Simulation duration & $1 \mathrm{hr}$ \\
\hline Network area & $1000 \mathrm{~m} \times 1000 \mathrm{~m}$ \\
\hline Number of mobile & 9,18 \\
\hline Mobility model & Closed loop \\
\hline Pause time & $1 \mathrm{sec}$ \\
\hline Data packet size & $1 \mathrm{~Kb}$ \\
\hline Number of CBR & $100 \%$ of MNs \\
\hline CBR rate & 1 packet per second \\
\hline Mobile node speed & $10 \mathrm{~km} / \mathrm{h}$ \\
\hline
\end{tabular}

www.iosrjournals.org 


\section{B. Results}

\section{B.1 Data dropped versus simulation time}

If the packet is received but the input buffer capacity has been exhausted, the frames may be dropped by the network. The OPNET has option of keeping track of this occurrence in the network operation.

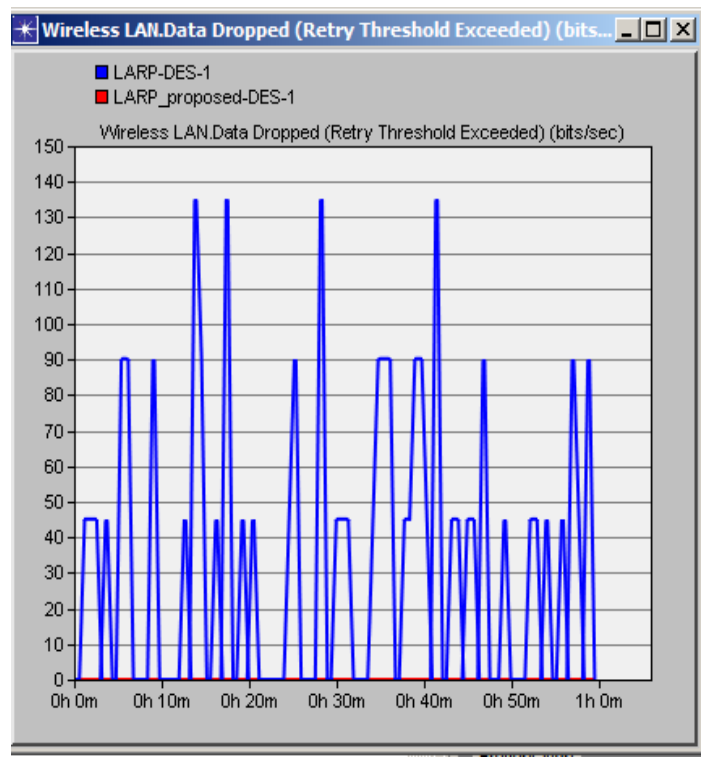

Figure 1: Data dropped in wireless LAN for 9 nodes

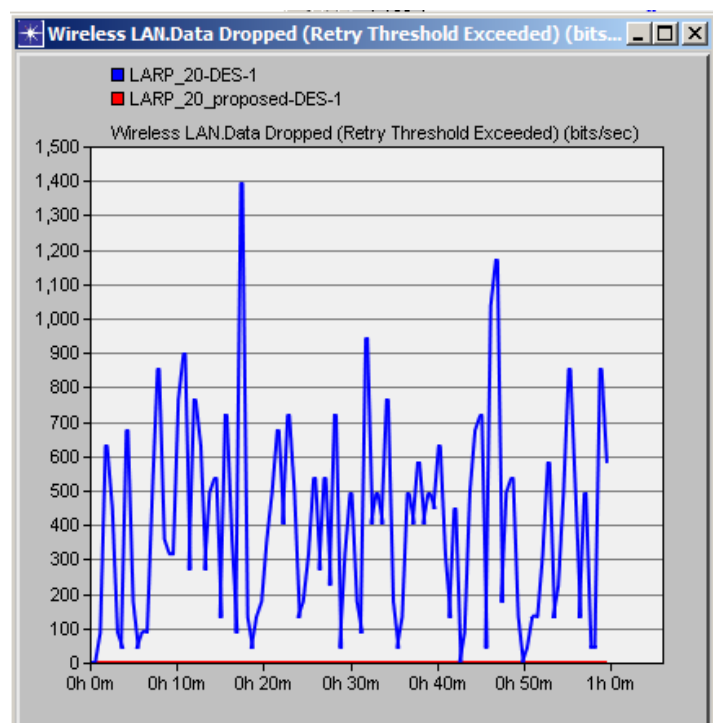

Figure 2: Data dropped in wireless LAN for 18 nodes.

Figure 1 and 2 shows that data dropped rate for 9 nodes are rising and falling in DSR and LAR routing protocol. While increasing the number of node in wireless LAN Data dropped has maximum for LAR routing protocol as compare to DSR protocol. In both cases, number of nodes is increasing in Wireless LAN data never dropped in LAR proposed protocol. The blue line shows graph for LAR protocol and the red line shows the graph for LAR proposed protocol.

\section{B.2 Retransmission Attempts versus Simulation time}


The source node sends the packet to the destination node if packets are lost or dropped during transmission. This graph shows the comparison for different scenarios.

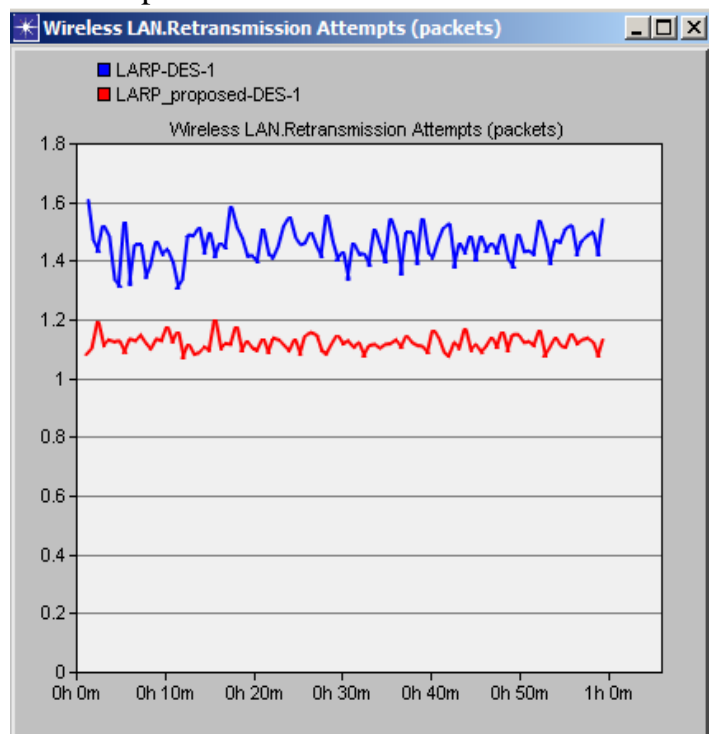

Figure 3: Retransmission attempts for 9 nodes.

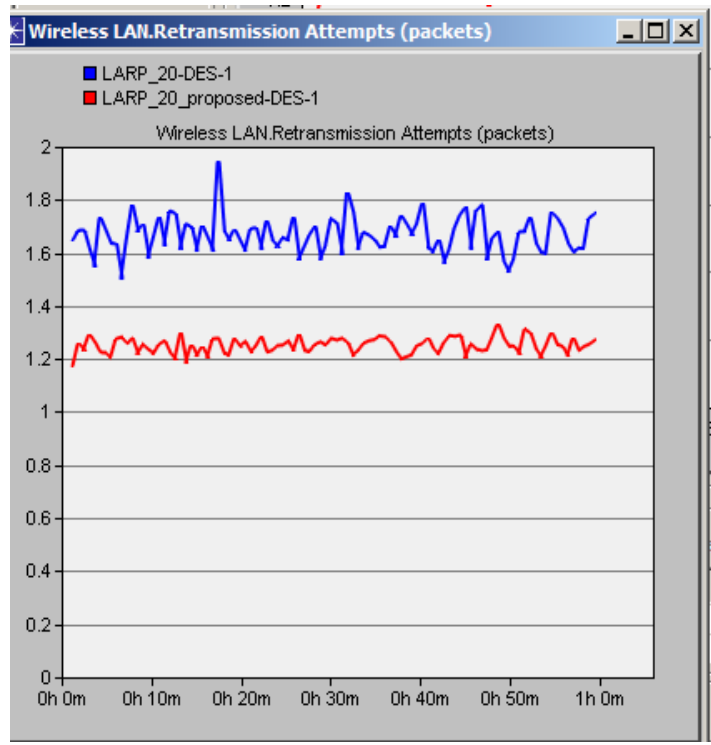

Figure 4: Retransmission attempts for 18 nodes

A figure 3 and 4 show that packets retransmission attempt in DSR protocol is lower than LAR and LAR proposed protocol. Packets retransmission attempt is varying between from 1.2 to 1.4 in LAR proposed protocol. While packet retransmission attempt in LAR protocol is higher than both protocol i.e. LAR protocol.

\section{CONCLUSION}

The paper has implemented three routing protocols LAR and proposed LAR for different scenarios in for Wireless LAN using the OPNET simulator. It found that LAR is not better for high density network. While number of nodes is less in Wireless LAN and proposed LAR is good for transmission of packet. Whenever increasing the number of nodes in Ad Hoc network LAR protocol does not get well results. In addition, simulation results show that data dropped rate is maximum in case of LAR protocol as compare to DSR because it does not search the location of destination node. Therefore, packet is always dropped during transmission. Retransmission of packets results show that LAR has maximum possibility to retransmission. Actual amount of 
data is successfully transmitted by proposed LAR protocol.

\section{ACKNOWLEDGEMENTS}

Authors are thankful to the Prof. Pramod K. Verma, Director General, M. P. Council of Science \& Technology, Bhopal to give permission to carry out this study. Authors are also thankful to Dr. Sandeep Goyal, Sr. Scientist and Head, MPRA Division, M. P. Council of Science \& Technology, Bhopal for his support, encouragement and providing valuable guidance in carrying out this study. Authors are also thankful to Dr. G.P. Basal,PG Head and Dr. C. L. Saxena, Director, Technocrats Institute of Technology, Bhopal, for his support.

\section{REFERENCES.}

[1] Tracy Camp, Jeff Boleng, Brad Williams, Lucas Wilcox, William Navidi, "Performance Comparison of Two Location Based Routing Protocols for Ad Hoc Networks", Proceedings of the 21st Annual Joint Conference of the IEEE Computer and Communications Societies (INFOCOM 2002), pages 1678-1687, 2002

[2] http://webhome.csc.uvic.ca/ wkui/Courses/wireless/Lecture4.pdf.

[3] Young Bae Ko. and Nitin H. Vaidya, "Location-Aided Routing (LAR) in mobile ad hoc networks", in Proc. 4th annual ACM/IEEE international conference on Mobile computing and networking, 1998.

[4] Young Bae Ko. , Nitin H. Vaidya, "Location-Aided Routing (LAR) in mobile ad hoc networks" Wireless Networks, Vo. 6 issue 4 pp. 307-321,July 2000.

[5] Angajala Srinivasa Rao, Somu Ventateswarku, Gogineni Rajesh Chandra, “ LAR Protocol for Ad Hoc Wireless Networks using GPS", March 2009

[6] V. Hnatyshin, M. Ahmed, R. Cocco, D. Urbano, “A comparative study of location aided routing protocols for MANET" , Wireless Days (WD), IFIP 2011.

[7] F. De Rango, A. Iera, A. Molinaro, S. Marano, "Multi-step increase of the forwarding zone for LAR protocol in ad hoc networks", Proceeding of the 57th IEEE Semiannual Vehicular Technology Conference(2003), Vol. 1, pp. 186 - 190, 2003.

[8] F. De Rango, A. Iera, A. Molinaro, S. Marano, "A modified location-aided routing protocol for the reduction of control overhead in ad-hoc wireless networks" Proceeding of 10th international Conference on Telecommunications (2003), Vol. 2, pp. 1033-1037, 2003.

[9] H. Al-Bahadili, " LAR-1P: An Efficient Hybrid Route Discovery Algorithm for MANETs", Proceeding of the 5th International Workshop on Performance Evaluation for Wireless Ad Hoc, Sensor, and Ubiquitous Networks (PE-WASUN 2008), 2008.

[10] Dipankar Deb, Srijita Barman Roy, and Nabendu Chaki, "LACBER: A New Location Aided Routing Protocol For GPS Scarce MANET", International Journal of Wireless \& Mobile Networks (IJWMN), Vol 1, No 1, August 2009. 